\title{
Surface roughness prediction of particulate composites using artificial neural networks in turning operation
}

\author{
Mohammad Ramezani*
}

Department of Mechanical Engineering, College of Engineering, Shiraz Branch, Islamic Azad University, Shiraz, Iran

\begin{tabular}{l}
\hline C H R O N I C L E \\
\hline Article history: \\
Received December 10, 2014 \\
Received in revised format: \\
March 2, 2015 \\
Accepted March 2, 2015 \\
Available online \\
March 2 2015 \\
\hline Keywords: \\
Artificial Neural Network (ANN) \\
Turning \\
Surface Roughness Particulate \\
Reinforced Aluminum Matrix \\
Composites (PAMCs) \\
\end{tabular}

\section{A B S T R A C T}

A number of factors, e.g. cutting speed and feed rate, affect the surface roughness in machining process. In this paper, an Artificial Neural Network model was used to forecast surface roughness with related inputs, including cutting speed and feed rate. The output of the ANN model input parameters related to the machined surface roughness parameters. In this research, twelve samples of experimental data were used to train the network. Moreover, four other experimental tests were implemented to test the network. The study concludes that ANN was a reliable and accurate method for predicting machining parameters in CNC turning operation of Particulate Reinforced Aluminum Matrix Composites (PAMCs) specimens with $0 \%, 5 \%$, $10 \%$ and $15 \%$ filler. The aim of this work is to decrease the production cost and consequently increase the production rate of these materials for industry without any trial and error method procedure.

\section{Introduction}

Surface finish is an important factor in quality of products. There have been several studies conducted to improve surface finish under the influence of various factors, but the outcome has not been satisfactory because of the complicated interaction among different factors (Groover, 2013). Many researchers have tried to estimate surface roughness and other machining parameters; some of them have focused on experimental studies, while others have created a prediction model and only used limited number of experimental data to test their models (Zhong et al., 2006). In recent years, thanks to the technology in modern industry, manufacturers have attempted to produce high quality products with increasing production rate and decreasing production costs. There are numerous factors which are associated with surface roughness (Ramezani, \& Afsari, 2015). Some of the most important factors affecting these activities are associated with machining parameters (Childs, 2000). Cutting speed and feed rates also influence on the optimum machining conditions (Jafarian et al., 2013). In machining process, several parameters simultaneously influence on the desired output. In addition, implementing

* Corresponding author.

E-mail address: Mohammad.Ramezani@Live.com (M. Ramezani) 
experimental tests is relatively time consuming and expensive. In order to solve these problems, prediction models can be used to find the output parameters through a change in inputs parameters (Sharma et al., 2008; Zain et al., 2010). It is hard to solve a forecasting problem and to consider all of machining parameters without using a model with the help of computer (Zhong et al., 2006). In order to predict, Artificial Neural Network (ANN) is a powerful and reliable method for the estimation of machining process parameters (Özel et al., 2007). ANN trains a model to solve non-linear problems and to extract the best output values through the use of input data. Therefore, it needs adequate inputs and outputs to train the network (Reddy et al., 2011). In this article, ANN model is used to predict the surface roughness in Particulate Reinforced Aluminum Matrix Composites (PAMCs) turning. PAMCs have the greatest importance among different classes of composites. They are less expensive and have better mechanical properties as compared with other engineering materials. They can be subject to various machining forming processes. Generally composites perform good balance between physical and mechanical properties (Rao \& Bhagyashekar, 2014; Surappa, 2003)

\section{Artificial Neural Networks}

Artificial Neural Network (ANN) uses non-linear train procedure (Ramezani, \& Afsari, 2015) and it is an effective method for prediction (Davalo, \& Naïm, 1991). ANN is also a reliable method to predict the cutting parameters (Reddy et al., 2011). The results in predictions of surface roughness in turning process prove the reliability and accuracy to forecast surface roughness (Zhong et al., 2006). To predict the surface roughness, back propagation is a method to minimize a squared error and has the capability to connect the input and output parameters (Aleksander, \& Morton, 1995). In back propagation method, an artificial ANN model is trained based on the given data following Bayesian Regulation training method. It trains the network based on Levenberg-Marquardt optimization. Bayesian regularization is a method of minimization to connect input and output parameters with neurons. It is an effective method especially when the dataset size is small (Demuth, \& Beale, 2000). Input layer gets its parameters from conducted experiments, hidden layer also receives the required information from the input layer and output layer receives its required information from the ANN model (Surjya, 2005). The number of neurons and layers are key factors for efficient implementation of the network for solving the prediction problem (Reddy et al., 2011).

In addition, the machining parameters are predicted through experimental data rather than algorithmic calculation (Ezugwu, 1995). The input and output dataset include 16 patterns where $75 \%$ of them are randomly selected as training data and $25 \%$ are randomly implemented to test the model. In this paper, the ANN model is validated in terms of agreement with experimental results through computing the difference between actual and predicted values.

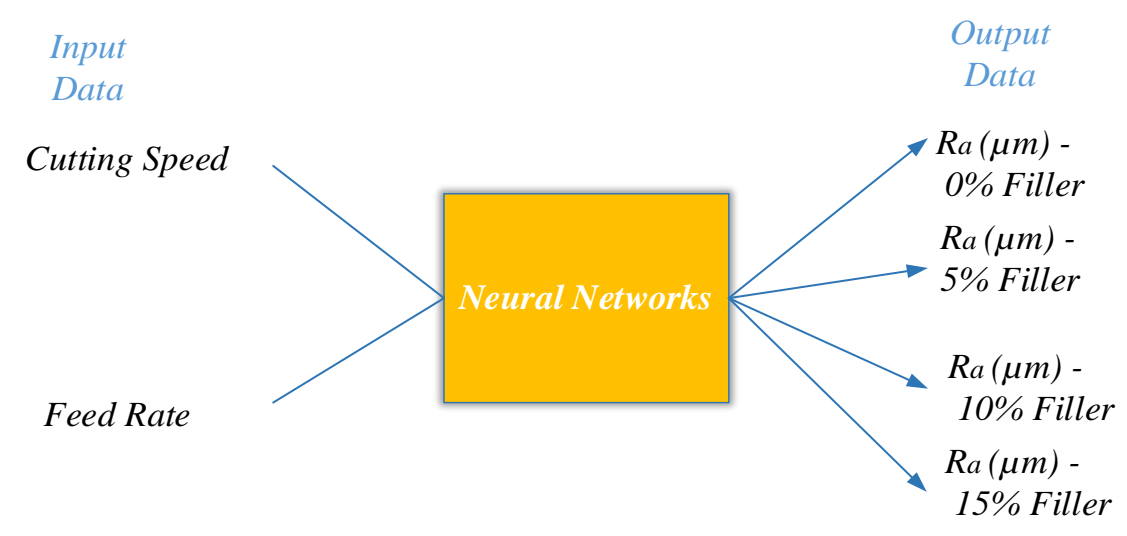

Fig. 1. The ANN model 


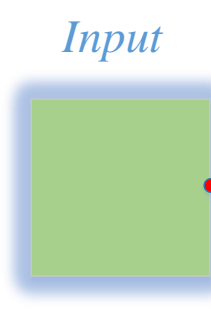

2

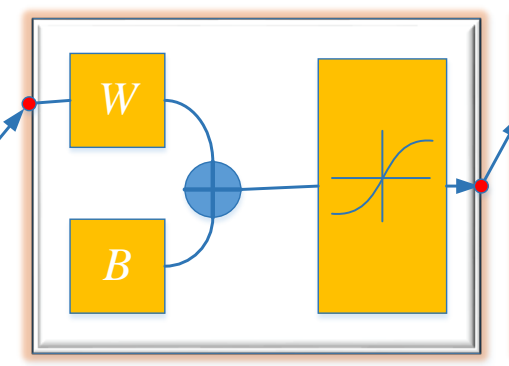

10

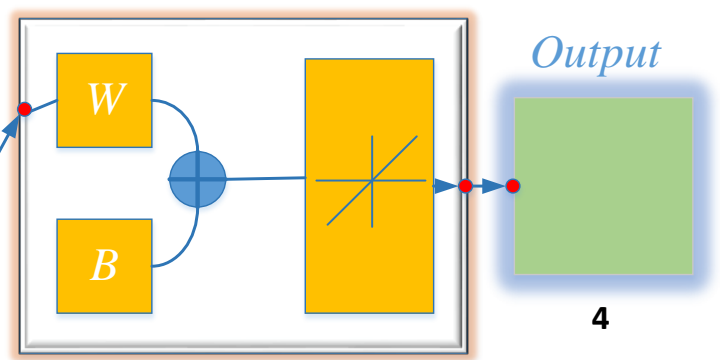

4

Fig. 2. Schematic diagram of ANN

\subsection{Collection of input/output dataset}

This experiment is performed on JOBBER XL CNC lathe of ACE Designers with Al turning tool holder and the K10 grade Carbide insert was used for machining process. Cast Al6061 material was selected as the matrix material and fly-as as the reinforcing phase for this composite. The specimens' sizes are 100mm diameter and $300 \mathrm{~mm}$ length each (Rao \& Bhagyashekar, 2014). The machining operation carried out with these conditions: (Rao \& Bhagyashekar, 2014)

- Cutting speed of 300 to $600 \mathrm{~m} / \mathrm{min}$ in steps of $100 \mathrm{~m} / \mathrm{min}$,

- Feed rate of 0.06 to $0.24 \mathrm{~mm} /$ revolution in steps of $0.06 \mathrm{~mm} /$ revolution,

- The depth of cut of $1.2 \mathrm{~mm}$ which is equal to three times the nose radius.

While turning operation with different cutting speed and feed rate, the Surface roughness was measured (Rao \& Bhagyashekar, 2014).

As Table 1 indicates, 12 number of tests (for each one) with different cutting forces, feed rate, depth of cut and tool radius noise were applied. For each sample, the value of Ra was measured. Then these values were used as training dataset for ANN model. Finally, four other experiments with random inputs (for each one) were conducted for testing the reliability of ANN model (See Table 2).

Table 1

Measurement Results (Rao \& Bhagyashekar, 2014)

\begin{tabular}{lcccccc}
\hline Nos. & $\begin{array}{c}\text { Feed per revolution } \\
(\mathrm{mm})\end{array}$ & $\begin{array}{c}\text { Cutting speed } \\
(\mathrm{m} / \mathrm{min})\end{array}$ & 0 \% Filler & 5 \% Filler & 10\% Filler & 15\% Filler \\
\hline 1 & 0.06 & 300 & 0.5936 & 0.513 & 0.387 & 0.684 \\
2 & 0.06 & 400 & 0.4536 & 0.442 & 0.360 & 0.624 \\
3 & 0.06 & 500 & 0.4128 & 0.380 & 0.340 & 0.532 \\
4 & 0.12 & 300 & 0.8952 & 0.748 & 0.591 & 0.902 \\
5 & 0.12 & 500 & 0.6408 & 0.606 & 0.536 & 0.701 \\
6 & 0.12 & 600 & 0.6264 & 0.596 & 0.499 & 0.665 \\
7 & 0.18 & 300 & 1.308 & 1.102 & 0.822 & 1.336 \\
8 & 0.18 & 400 & 1.114 & 1.006 & 0.864 & 1.261 \\
9 & 0.18 & 600 & 0.988 & 0.811 & 0.709 & 1.081 \\
10 & 0.24 & 400 & 1.381 & 1.216 & 1.102 & 1.362 \\
11 & 0.24 & 500 & 1.258 & 1.058 & 0.896 & 1.244 \\
\hline
\end{tabular}




\section{Table 2}

Testing the network with new samples

\begin{tabular}{|c|c|c|c|c|c|}
\hline \multirow{2}{*}{\multicolumn{2}{|c|}{ Feed per revolution (mm) }} & Condition 1 & Condition 2 & Condition 3 & Condition 4 \\
\hline & & 0.06 & 0.12 & 0.18 & 0.24 \\
\hline \multicolumn{2}{|c|}{ Cutting speed (m/min) } & 600 & 400 & 500 & 300 \\
\hline $0 \%$ & Actual $R_{a}(\mu m)$ & 0.3716 & 0.7536 & 1.011 & 1.569 \\
\hline \multirow{2}{*}{ Filler } & Predicted $\mathrm{R}_{\mathrm{a}}(\mu \mathrm{m})$ & 0.3906 & 0.7062 & 1.0139 & 1.5752 \\
\hline & $\%$ error $R_{a}(\mu \mathrm{m})$ & -5.130 & 6.2898 & -0.2868 & -0.3952 \\
\hline $5 \%$ & Actual $R_{a}(\mu \mathrm{m})$ & 0.311 & 0.674 & 0.839 & 1.332 \\
\hline \multirow{2}{*}{ Filler } & Predicted $\mathrm{R}_{\mathrm{a}}(\mu \mathrm{m})$ & 0.3678 & 0.6627 & 0.8708 & 1.3328 \\
\hline & $\%$ error $R_{a}(\mu m)$ & -18.2637 & 1.6766 & -3.7902 & -0.0601 \\
\hline $10 \%$ & Actual $R_{a}(\mu m)$ & 0.289 & 0.567 & 0.725 & 1.164 \\
\hline \multirow{2}{*}{ Filler } & Predicted $\mathrm{R}_{\mathrm{a}}(\mu \mathrm{m})$ & 0.2739 & 0.6460 & 0.7360 & 1.1448 \\
\hline & $\%$ error $R_{a}(\mu m)$ & 5.2249 & -13.933 & -1.5172 & 1.6495 \\
\hline $15 \%$ & Actual $R_{a}(\mu \mathrm{m})$ & 0.411 & 0.788 & 1.123 & 1.497 \\
\hline \multirow{2}{*}{ Filler } & Predicted $\mathrm{R}_{\mathrm{a}}(\mu \mathrm{m})$ & 0.4691 & 0.8036 & 1.1590 & 1.4587 \\
\hline & $\%$ error $R_{a}(\mu m)$ & -14.1363 & -1.9797 & -3.2057 & 2.5585 \\
\hline
\end{tabular}

\section{Results}

Mean Squared Error (MSE) between network outputs and target values is used in ANN's model. First, the maximum number of 1000 epochs was set to stop the training, but after some iterations it was terminated because there was no progress in the achieved MSE. As illustrated in Fig. 3, the best training performance is $8.7888 \mathrm{e}-14$ at epoch 915 , which is a low prediction error measured with MSE.

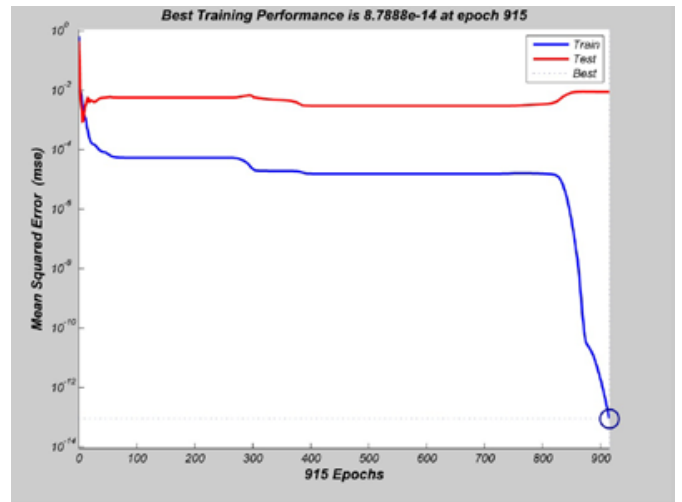

Fig. 3. Mean Square Error-Number of Epochs

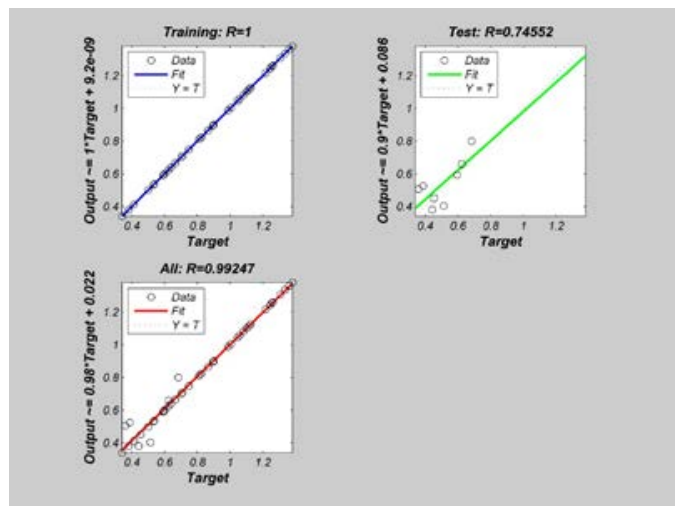

Fig. 4 Correlation Coefficient (Targets-Outputs)

Correlation Coefficient (R) is performance measure relation strength between experimental and predicted values. As shown in Fig. 4, their values are close to each other. Error histogram is depicted in Fig. 5. It is based on [actual output-predicted output]. Zero point is the minimum point in which the possibility of error lies. The large peak at zero point means small difference between experimental outputs and predicted values; however, small peak shows incorrect values. Moreover, it reveals the large difference between output data and predicted output. Prediction error have been calculated with

$$
\text { Error }=\frac{(\text { Actual value }- \text { Predicted value }) \times 100}{\text { Predicted value }}
$$

Fig. 6 to Fig. 9 show the difference between actual and predicted values for four samples to show the amount of error in using ANN method. 


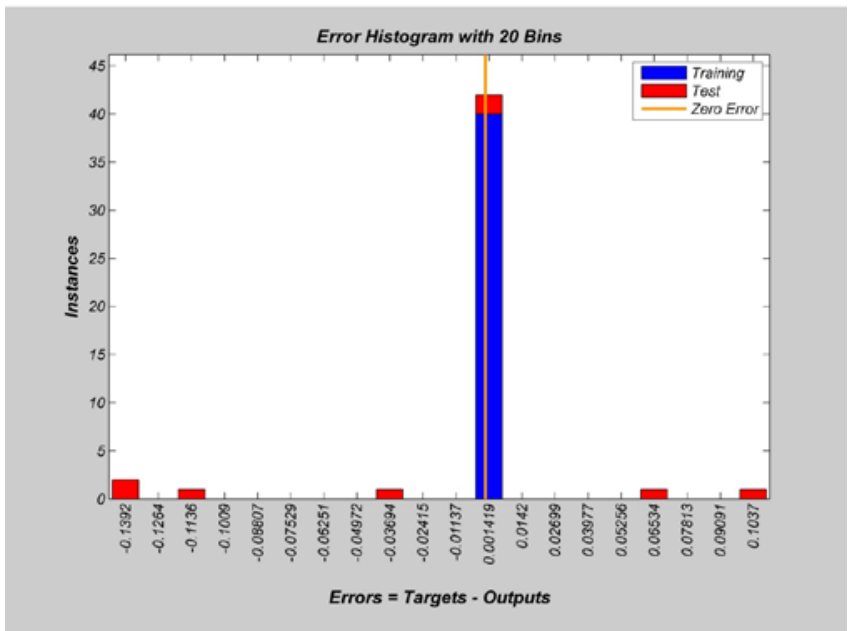

Fig. 5. Error Histogram results simulation

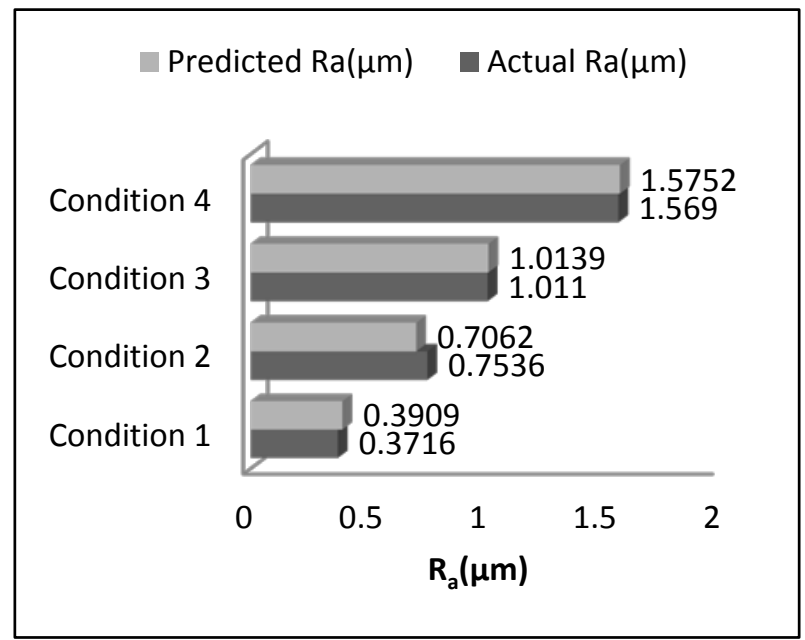

Fig. 6. Comparison of Ra values obtained from actual measurements and ANN method-(sample No. Vs. Ra $(\mu \mathrm{m}))$ - For 0\% Filler

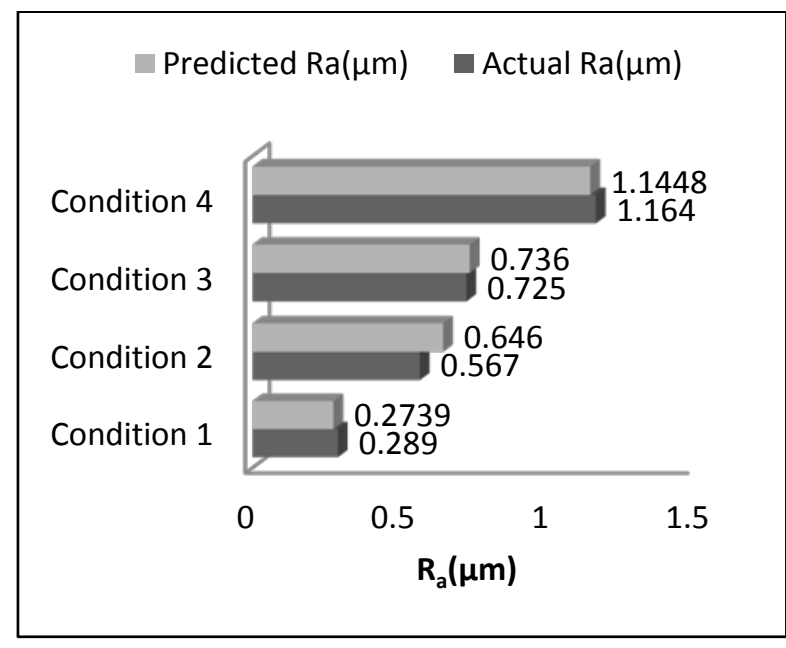

Fig. 8. Comparison of Ra values obtained from actual measurements and ANN method-(sample No. Vs. Ra $(\mu \mathrm{m}))$ - For $10 \%$ Filler

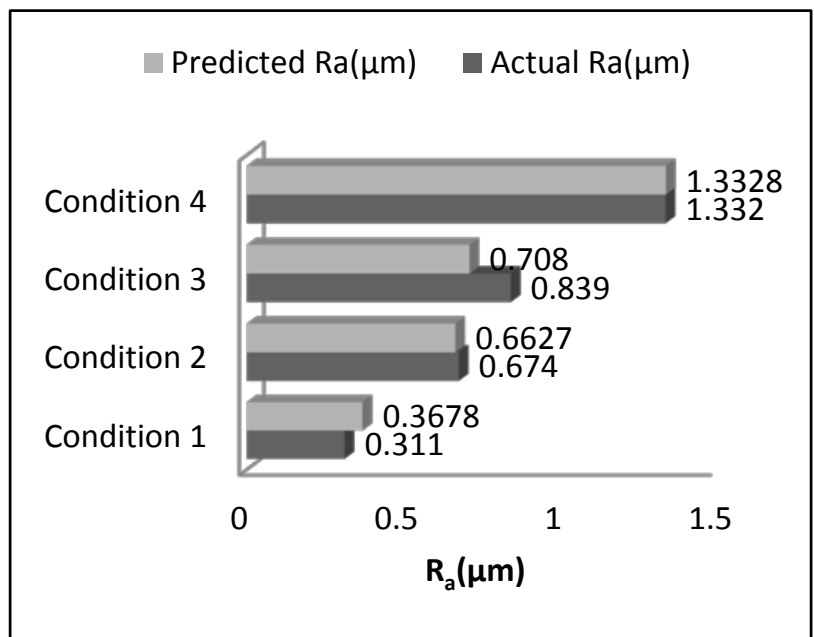

Fig. 7. Comparison of Ra values obtained from actual measurements and ANN method-(sample No. Vs. Ra $(\mu \mathrm{m}))$ - For $\mathbf{5 \%}$ Filler

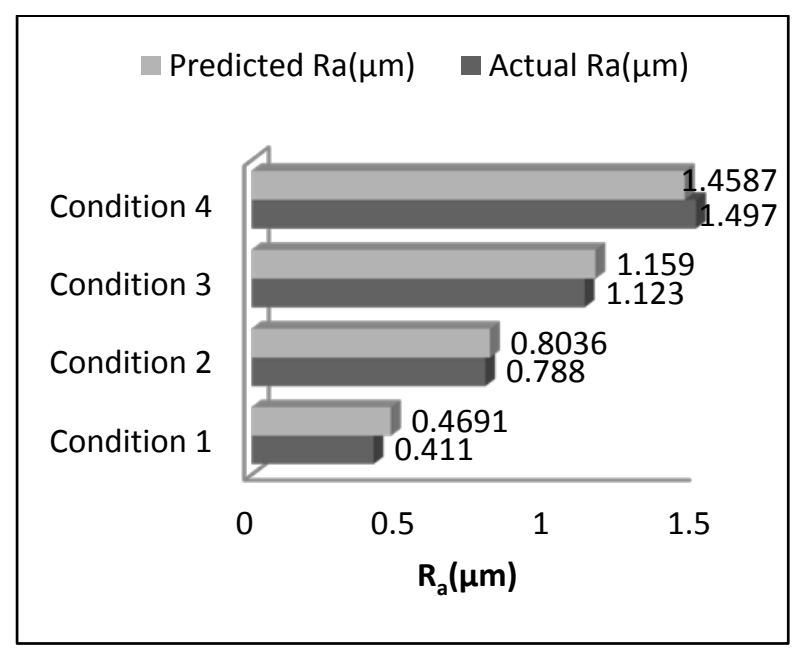

Fig. 9. Comparison of Ra values obtained from actual measurements and ANN method-(sample No. Vs. Ra $(\mu \mathrm{m}))$ - For 15\% Filler 


\section{Conclusion}

We have predicted the surface roughness and cutting forces for CNC turning using ANN with four inputs. These included turning speed, feed rate, depth of cut and tool noise radius. The reliability of network was tested and observed by finding the error percentage between data from eight new samples and predicted data.

\section{References}

Aleksander, I., \& Morton, H. (1995). An introduction to neural computing. London: International Thomson Computer Press.

Childs, T. (2000). Metal machining: Theory and applications. London: Arnold.

Davalo, E., \& Naïm, P. (1991). Neural networks. London: Macmillan.

Demuth, H., \& Beale, M. (2000). Matlab Neural Network Toolbox User's Guide.

Ezugwu, E. O., Arthur, S. J., \& Hines, E. L. (1995). Tool-wear prediction using artificial neural networks. Journal of materials Processing technology, 49(3), 255-264.

Groover, M. P. (2002). Solutions manual: fundamentals of modern manufacturing. Wiley.

Jafarian, F., Taghipour, M., \& Amirabadi, H. (2013). Application of artificial neural network and optimization algorithms for optimizing surface roughness, tool life and cutting forces in turning operation. Journal of Mechanical Science and Technology, 27(5), 1469-1477.

Özel, T., Karpat, Y., Figueira, L., \& Davim, J. P. (2007). Modelling of surface finish and tool flank wear in turning of AISI D2 steel with ceramic wiper inserts. Journal of Materials Processing Technology, 189(1), 192-198.

Ramezani, M., \& Afsari, A., (2015). Surface roughness and cutting force estimation in the CNC turning using artificial neural networks. Management Science Letters. Vol. 5, Issue 4. 357-362.

Rao, C. P., \& Bhagyashekar, M. S. (2014). Effect of machining parameters on the surface roughness while turning particulate composites. Procedia Engineering, 97, 421-431.

Reddy, V. D., Krishnaiah, G. A., Kumar, H., \& Priya, S. K. (Dec., 2011). ANN Based Prediction of Surface Roughness in Turning, International Conference on Trends in Mechanical and Industrial Engineering (ICTMIE'2011) Bangkok

Sharma, V. S., Dhiman, S., Sehgal, R., \& Sharma, S. K. (2008). Estimation of cutting forces and surface roughness for hard turning using neural networks. Journal of Intelligent Manufacturing, 19, 473483.

Surappa, M. K. (2003). Aluminium matrix composites: Challenges and opportunities. Sadhana, 28(12), 319-334.

Pal, S. K., \& Chakraborty, D. (2005). Surface roughness prediction in turning using artificial neural network. Neural Computing \& Applications, 14(4), 319-324.

Zain, A. M., Haron, H., \& Sharif, S. (2010). Prediction of surface roughness in the end milling machining using Artificial Neural Network. Expert Systems with Applications, 37(2), 1755-1768.

Zhong, Z. W., Khoo, L. P., \& Han, S. T. (2006). Prediction of surface roughness of turned surfaces using neural networks. The International Journal of Advanced Manufacturing Technology, 28(7-8), 688-693. 